\title{
Cyclovirobuxinum D suppresses lipopolysaccharide- induced inflammatory responses in murine macrophages in vitro by blocking JAK-STAT signaling pathway
}

\author{
Dan $\mathrm{GUO}^{1}$, Jing-rong $\mathrm{LI}^{2}$, Ying WANG ${ }^{3}$, Lin-sheng $\mathrm{LEI}^{2}$, Chuan-lin $\mathrm{YU}^{2}$, Na-na $\mathrm{CHEN}^{2, *}$ \\ ${ }^{1}$ Nanfang Hospital, Southern Medical University, Guangzhou 510515, China; ${ }^{2}$ School of Pharmaceutical Sciences, Southern Medical \\ University, Guangzhou 510515, China; ${ }^{3}$ China National Center for Biotechnology Development, Beijing 100039, China
}

\begin{abstract}
Aim: Cyclovirobuxinum D (CVB-D), an alkaloid isolated from the Chinese medicinal plant Buxus microphylla, has been found to be effective to treat cardiac insufficiency, arrhythmias and coronary heart disease. In the present study, we investigated the effects of CVB-D on the inflammatory responses in lipopolysaccharide (LPS)-stimulated murine macrophages in vitro and the underlying mechanisms.

Methods: Murine macrophage cell line RAW264.7 cells were incubated in the presence of LPS $(0.1 \mu \mathrm{g} / \mathrm{mL})$ for $24 \mathrm{~h}$. The cell viability was measured using MTT assay. The release of NO and cytokines were detected using the Griess test and ELISA, respectively. The mRNA and protein levels were determined using RT-PCR and Western blot, respectively. Reporter gene assays were used to analyze the transcriptional activity of NF-KB.

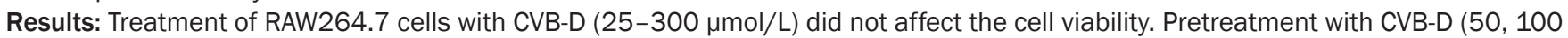
and $200 \mu \mathrm{mol} / \mathrm{L}$ ) concentration-dependently decreased NO release and iNOS expression in LPS-treated RAW264.7 cells (its $\mathrm{IC}_{50}$ value in inhibition of NO production was $144 \mu \mathrm{mol} / \mathrm{L})$. CVB-D also concentration-dependently inhibited the secretion and mRNA expression of IL-1 1 and IL-6 in LPS-treated RAW264.7 cells. Furthermore, CVB-D remarkably inhibited the phosphorylation of STAT1 and STAT3, as well as JAK2 in LPS-treated RAW264.7 cells, but did not affect the activation of NF-KB and MAPKs pathways. Pretreatment with the JAK2 specific inhibitor AG490 (30 $\mathrm{mmol} / \mathrm{L})$ produced similar effects on NO release and iNOS expression in LPS-treated RAW264.7 cells. Conclusion: CVB-D exerts anti-inflammatory effects in LPS-stimulated murine macrophages in vitro at least in part by blocking the JAKSTAT signaling pathway. The anti-inflammatory actions of CVB-D may contribute to its cardioprotection.
\end{abstract}

Keywords: cyclovirobuxinum D; macrophage; inflammation; nitric oxide; cytokine; JAK; STAT; myocardial infarction; cardioprotection

Acta Pharmacologica Sinica (2014) 35: 770-778; doi: 10.1038/aps.2014.16; published online 21 Apr 2014

\section{Introduction}

Macrophages play an important role in the pathogenesis of inflammation by secreting various inflammatory mediators, such as NO, prostaglandin E2 (PGE2), tumor necrosis factor alpha (TNF-a), IL-1, and IL-6 $6^{[1-3]}$. Overproduction of these mediators may lead to tissue damage and cause inflammatoryrelated diseases ${ }^{[4,5]}$. A growing body of evidence suggests that accentuation of the post-infarction inflammatory response results in poorer remodeling and dysfunction following myocardial infarction ${ }^{[6,7]}$.

\footnotetext{
* To whom correspondence should be addressed.

E-mail gdcnn_2011@126.com

Received 2013-11-20 Accepted 2014-02-20
}

CVB-D, (3ß, 5a, 16a, 20S)-4, 4,14-trimethyl-3,20-bis(methylamino)-9,19-cyclopregnan-16-ol, is an alkaloid extracted from the Chinese traditional plant Buxus microphylla. It has been widely used in the treatment of heart-related conditions, such as arrhythmias and coronary heart disease in China ${ }^{[8-10]}$. More recent studies have shown that CVB-D can ameliorate heart failure induced by myocardial infarction ${ }^{[11,12]}$. However, the exact mechanism behind its therapeutic basis is not clear. Clearance of necrotic debris by neutrophils, monocytes, and macrophages is a critical component of infarct healing. Nevertheless, tight control and timely repression of this inflammatory response are important to prevent excessive tissue degradation and adverse cardiac remodeling, which would lead to infarct expansion and heart failure. Therapies block- 
ing pro-inflammatory pathways have been found to improve wound healing and to reduce the risk of heart failure in acute myocardial infarction ${ }^{[13,14]}$.

Anti-inflammatory mechanisms and therapeutic opportunities in myocardial infarction and heart failure encouraged us to evaluate the anti-inflammatory effects and cardioprotective mechanism of CVB-D in myocardial ischemia. In the present study, we used the model of LPS-evoked murine macrophagelike cells RAW264.7 to investigate the anti-inflammatory action of this compound. LPS activates a set of intracellular signaling cascades in stimulated macrophages, including the nuclear factor kappa B (NF-kB), mitogen-activated protein kinases (MAPK) and Janus kinase-signal transducer and activator of transcription (JAK-STAT) pathways. These signaling pathways then regulate the expression of genes encoding various inflammatory mediators ${ }^{[15-17]}$. The effects of CVB-D on the production of inflammatory mediators and related intracellular signaling pathways were evaluated in this study.

\section{Materials and methods Reagents}

Cyclovirobuxinum D (purity: $98 \%$ by HPLC) was purchased from MUST BIO-TECHNOLOGY CO, LTD (Chengdu, China). Lipopolysaccharide (LPS), AG490 and 3-(4,5-dimethylthiazol2-yl)-2,5-diphenyltetrazolium bromide (MTT) were obtained from Sigma-Aldrich (St Louis, MO, USA). Two-step MMLV Platinum SYBR Green qPCR SuperMix-UDG kit, Novex ECL HRP Chemiluminescent substrate reagent kit and Lipofectamine 2000 were obtained from Invitrogen (San Diego, CA, USA). Griess reagent was purchased from Beyotime Institute of Biotechnology (Haimen, China). Antibodies against inducible nitric oxide synthase (iNOS), cyclooxygenase (COX)-2, p65, JAK2, p-JAK2 (Tyr1007/1008), STAT1, p-STAT1 (Tyr-701), STAT3, p-STAT3 (Tyr-705), and GAPDH were obtained from Cell Signaling Technology (Danvers, MA, USA). Antibodies against total and phosphorylated p38, the p42/p44 extracellular regulated kinases 1 and 2 (ERK1/2), and c-Jun N-terminal kinases (JNKs) were obtained from Bioword Technology, Inc (St Louis, MN, USA). Antibodies against IkB- $\alpha$ and PPAR and HRP-conjugated goat-anti-rabbit IgG antibody were obtained from Santa Cruz (Santa Cruz, CA, USA). The Luciferase Assay Kit was obtained from Promega (Madison, CA, USA). The pNF-kB-luciferase plasmid was kindly provided by the Antiviral Research Center of Southern Medical University in China. The IL-1, IL-6, and TNF-a ELISA kits were purchased from eBiosciences (San Diego, CA, USA). CVB-D was dissolved in DMSO and diluted in culture media. The final concentration of DMSO never exceeded $0.1 \%$.

\section{Cell culture}

The murine macrophage cell line RAW264.7 was obtained from the China Center for Type Culture Collection (Shanghai, China). Cells were grown in DMEM medium supplemented with $10 \%$ fetal bovine serum (Invitrogen), $100 \mathrm{IU} / \mathrm{mL}$ penicillin and $100 \mu \mathrm{g} / \mathrm{mL}$ streptomycin in a humidified incubator containing $5 \% \mathrm{CO}_{2}$ at $37^{\circ} \mathrm{C}$.

\section{Cell viability assay}

Cell viability was measured using the MTT assay as described. Briefly, RAW264.7 cells at a density of $1 \times 10^{4}$ cells/well were seeded in 96-well plates overnight and treated with various concentrations of CVB-D (25-300 $\mu \mathrm{mol} / \mathrm{L})$ for $24 \mathrm{~h}$. Next, $20 \mu \mathrm{L}$ of MTT solution ( $5 \mathrm{mg} / \mathrm{mL}$ ) was added to each well, and the cells were cultured for another $4 \mathrm{~h}$ at $37^{\circ} \mathrm{C}$. The supernatant was removed and DMSO was added for solubilization of formazan. The optical density at $570 \mathrm{~nm}$ was measured by a microplate reader (Benchmark plus Bio-Rad Laboratories, CA, USA).

\section{Nitric oxide (NO) determination}

NO levels were determined by measuring its stable oxidative metabolite nitrite levels in the culture media using the Griess reaction as previously described ${ }^{[18]}$. Briefly, RAW 264.7 cells $\left(2 \times 10^{5}\right.$ cells/well) were plated in 24 -well plates followed by incubation with various concentrations of CVB-D (50-200 $\mu \mathrm{mol} / \mathrm{L})$ for $1 \mathrm{~h}$. Then, LPS $(0.1 \mu \mathrm{g} / \mathrm{mL})$ was added into the culture medium for another $24 \mathrm{~h}$ of incubation. Next, $50 \mu \mathrm{L}$ supernatant and $100 \mu \mathrm{L}$ Griess reagent were reacted for $15 \mathrm{~min}$ and the nitrite content measured by absorbance at $540 \mathrm{~nm}$. The NO concentration was calculated using a standard curve prepared with sodium nitrite.

\section{Detection of cytokine production by enzyme-linked immuno- sorbent assay (ELISA)}

RAW264.7 cells were pretreated with different concentrations of CVB-D (50-200 $\mu \mathrm{mol} / \mathrm{L})$ for $1 \mathrm{~h}$ and then treated with 0.1 $\mu \mathrm{g} / \mathrm{mL}$ LPS for another $24 \mathrm{~h}$. The levels of IL-1 $\beta$, IL-6, and TNF- $\alpha$ in the culture media were measured using ELISA kits according to the manufacturer's instructions.

\section{Transient transfection and luciferase assay}

RAW264.7 cells were seeded into 96 -well plates $\left(4 \times 10^{4}\right.$ cells $/$ well) and incubated overnight. The pNF-kB-luciferase plasmid was transfected using lipofectamine 2000 according to the manufacturer's instructions. After $1 \mathrm{~h}$ of pretreatment with CVB-D and $8 \mathrm{~h}$ of incubation with LPS and CVB-D, the cells were lysed and the luciferase activity was determined using the Luciferase Assay Kit with a luminometer (Genios Pro, Tecan, USA).

\section{Western blot analysis}

Western blots were performed to investigate the effect of CVB-D on the protein levels of iNOS, COX-2, NF-кB, IкBa, and phosphorylated and total STAT1, STAT3, JAK2, and MAPKs. After RAW264.7 cells were incubated with LPS in the presence or absence of CVB-D, whole cell extract, nuclear and cytoplasmic proteins were prepared according to the protocol of the Protein Extraction Kit (Beyotime). Protein concentrations were determined using the BCA protein assay system (Beyotime). Aliquots of the lysates (20-50 $\mu \mathrm{g}$ protein) were separated on $8 \%-10 \%$ SDS-PAGE and transferred onto polyvinylidene difluoride membranes (BIO-RAD, CA, USA). After blocked with $5 \%$ bovine serum albumin in TBST $(0.1 \%)$, 
the membranes were incubated overnight at $4{ }^{\circ} \mathrm{C}$ with primary antibodies and then incubated with the peroxidase-conjugated secondary antibodies for $60 \mathrm{~min}$ at room temperature. The membranes were incubated with an enhanced chemiluminescence detection system (Pierce, Rockford, IL, USA) and exposed to X-ray film. The protein signals were quantified by densitometry analysis using a FluorChem Q System (Alpha Innotech, CA, USA).

RNA isolation and real-time Polymerase Chain Reaction (PCR) analysis

RAW 264.7 cells were plated at $1 \times 10^{6}$ cells/well in 12-well plates, then pretreated with CVB-D (50-200 $\mu \mathrm{mol} / \mathrm{L})$ for $1 \mathrm{~h}$ and incubated with LPS $(0.1 \mu \mathrm{g} / \mathrm{mL})$ for another $6 \mathrm{~h}$. Total RNA from RAW264.7 cells was prepared by Trizol reagent according to the manufacturer's protocol.

Total RNA $(1 \mu \mathrm{g})$ was reverse-transcribed with M-MuLV Reverse Transcriptase Kit to obtain cDNA. Real-time PCR was performed in an ABI7500 real-time PCR instrument (Applied Biosystems) with the SYBR Green qPCR SuperMixUDG kit. The comparative cycle threshold $\left(\Delta \Delta C_{T}\right)$ method of relative quantification was used to determine the fold-change of expression. A melting curve analysis was carried out after amplification to verify the accuracy of the amplicon. Primer sequences for qPCR of TNF- $\alpha$, IL-6, IL-1 $\beta$, iNOS, COX-2, and GAPDH mRNA are shown in Table 1.

\section{Statistical analysis}

All data are expressed as the means \pm SD. One-way ANOVA and two-tailed Student's $t$-test were used. $P$ values $<0.05$ were considered statistically significant. Statistical analyses were conducted with SPSS 13.0 (SPSS Inc, Chicago, IL, USA).

\section{Results}

CVB-D inhibited NO production, as well as the mRNA and protein expression of iNOS, in LPS-stimulated RAW264.7 cells

NO levels in the medium of RAW264.7 cells increased approximately 6.5-fold after LPS treatment (Figure 1A). CVB-D inhibited NO production in LPS-stimulated RAW264.7 cells in a dose-dependent fashion, with an $\mathrm{IC}_{50}$ of $144 \mu \mathrm{mol} / \mathrm{L}$. Because iNOS plays a vital role in NO production during inflammation, we performed Western blot and real-time PCR to determine whether the decreased level of $\mathrm{NO}$ was due to reduced iNOS expression. CVB-D was found to significantly inhibit the mRNA and protein expression of iNOS (Figure 1B and 1C). AG490, a specific JAK2 inhibitor, was found to have similar effects on $\mathrm{NO}$ release and iNOS mRNA expression (Figure 1A and 1C). PGE2, which is mainly produced through the COX-2 pathway, is another important inflammatory mediator in the initiation of inflammatory disorders to induce pain, fever and edema. In our study, CVB-D did not show any effects on the mRNA and protein levels of COX-2 in LPSstimulated RAW264.7 cells (data not shown).

The inhibitory effect of CVB-D on the production of inflammatory mediators was not due to cytotoxicity because the compound, even at a dose of up to $300 \mu \mathrm{mol} / \mathrm{L}$, did not significantly suppress the cell viability as measured by the MTT assay (Figure 1D).

CVB-D decreased LPS-induced IL-1 $\beta$ and IL-6 gene expression and protein secretion in RAW264.7 cells

CVB-D inhibited LPS-induced IL-1 $\beta$ and IL- 6 gene expression and protein secretion in a dose-dependent manner (Figure 2A and 2B). Treatment with $200 \mu \mathrm{mol} / \mathrm{L} \mathrm{CVB-D} \mathrm{led} \mathrm{to} \mathrm{a} 99 \%$ inhibition of IL-1 $\beta$ secretion and a $48 \%$ inhibition of IL- 6 secretion. Conversely, at the same concentration, CVB-D was unable to inhibit the secretion of TNF-a (Figure 2C). In addition, CVB-D markedly inhibited IL-1 $\beta$ and IL-6 mRNA expression (Figure 2D). CVB-D (200 $\mu \mathrm{mol} / \mathrm{L})$ inhibited IL-1 $\beta$ mRNA expression by $57 \%$ and inhibited IL- 6 mRNA expression by $28 \%$ in LPSstimulated RAW264.7 cells. However, no significant change was detected in TNF-a mRNA expression (Figure 2D). Similarly to CVB-D, AG490 also significantly inhibited IL-1 $\beta$ and IL-6 but not TNF-a release or gene expression.

CVB-D did not inhibit NF-KB nuclear translocation and IKB- $\alpha$ protein degradation stimulated by LPS in RAW264.7 cells

The NF-kB pathway has been reported to play important

Table 1. Primers used for real-time PCR analysis.

\begin{tabular}{|c|c|c|c|c|c|}
\hline mRNA & Primer & Sequence $\left(5^{\prime}-3^{\prime}\right)$ & GeneBank accession \# & Position & Size (bp) \\
\hline \multirow[t]{2}{*}{ IL-6 } & Sense & AGTTGCCTTCTTGGGACTGA & J03783 & $81-100$ & 191 \\
\hline & Antisense & CAGAATTGCCATTGGCACAAC & & $271-252$ & \\
\hline \multirow[t]{2}{*}{ TNF- $\alpha$} & Sense & GTGGAACTGGCAGAAGAGGC & NM_013693.2 & $184-203$ & 122 \\
\hline & Antisense & AGACAGAAGAGCGTGGTGGC & & $305-286$ & \\
\hline \multirow[t]{2}{*}{ iNOS } & Sense & TCCATGACTCCCAGCACA & NM_010927.3 & $215-232$ & 108 \\
\hline & Antisense & ССАТСТССТGСАТTTСТTCC & & $322-303$ & \\
\hline \multirow[t]{2}{*}{ IL-1及 } & Sense & GCAACTGTTCCTGAACTCAACT & NM_008361.3 & $72-93$ & 89 \\
\hline & Antisense & ATCTTTTGGGGTCCGTCAACT & & $140-160$ & \\
\hline \multirow[t]{2}{*}{ cox-2 } & Sense & GAAGTCTTTGGTCTGGTGCCTG & NM_011198.3 & $926-947$ & 133 \\
\hline & Antisense & GTCTGCTGGTTTGGAATAGTTGC & & $1058-1036$ & \\
\hline \multirow[t]{2}{*}{ GAPDH } & Sense & GGTGAAGGTCGGTGTGAACG & GU214026.1 & $49-68$ & 233 \\
\hline & Antisense & CTCGCTCCTGGAAGATGGTG & & $281-262$ & \\
\hline
\end{tabular}



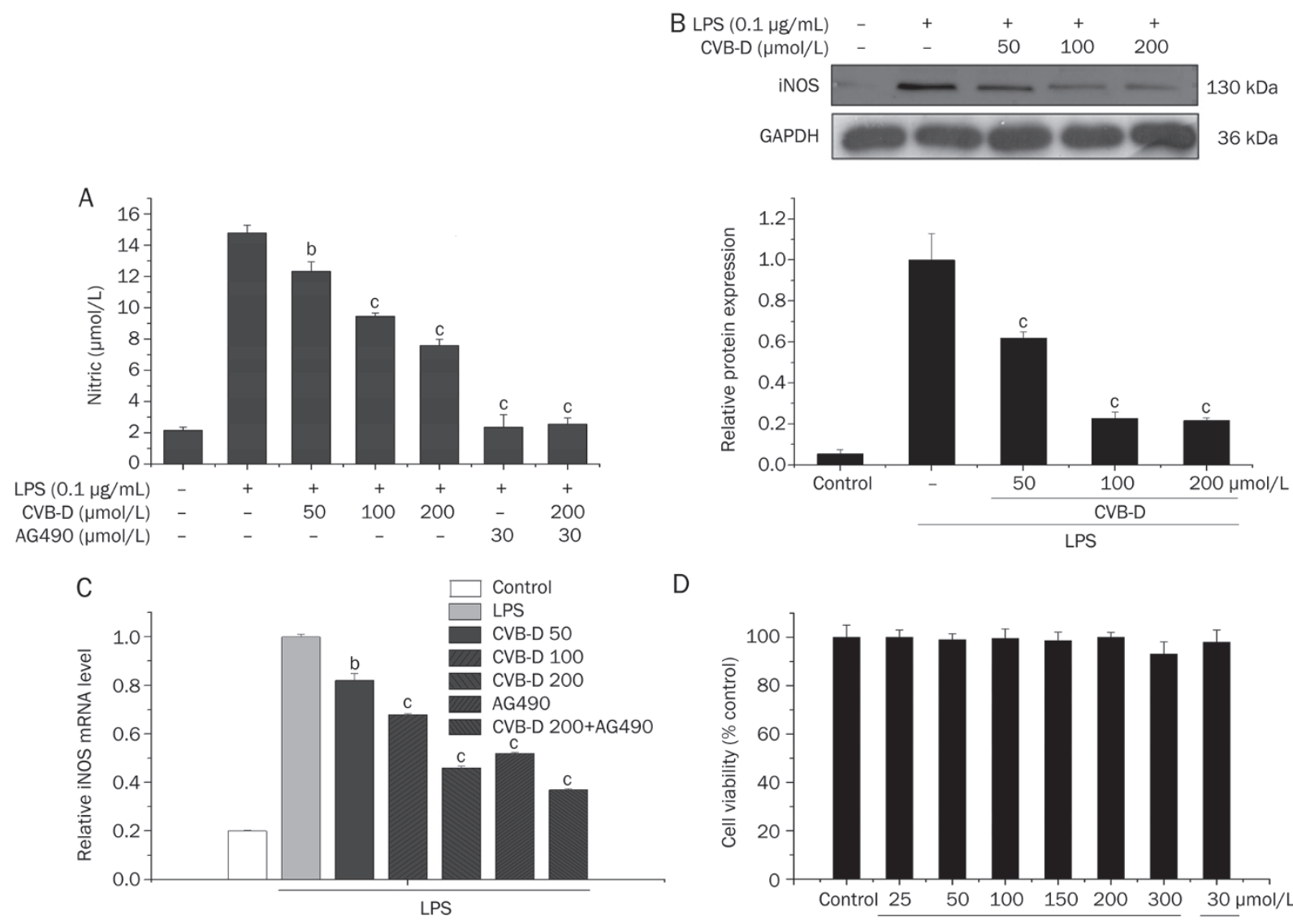

D

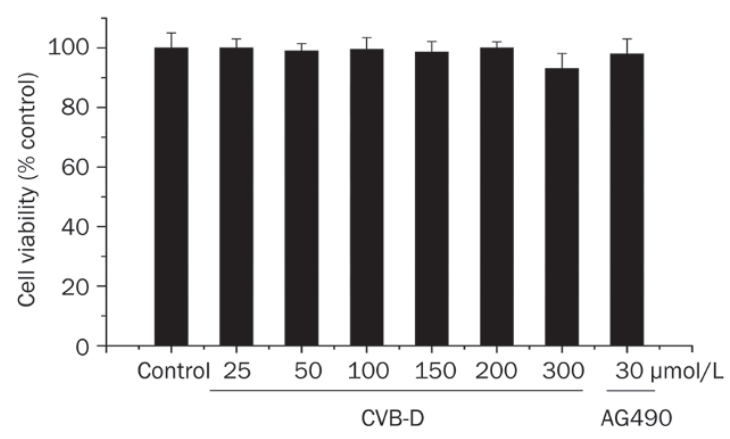

Figure 1. The inhibitory effect of CVB-D on LPS-induced NO production and iNOS expression in RAW264.7 cells. After RAW264.7 cells were pretreated with CVB-D (50-200 $\mu \mathrm{mol} / \mathrm{L})$ or AG490 $(30 \mu \mathrm{mol} / \mathrm{L})$ for $1 \mathrm{~h}$ and incubated with LPS $(0.1 \mu \mathrm{g} / \mathrm{mL})$ for another $24 \mathrm{~h}$, (A) NO levels were measured using the Griess reagent, and (B) protein expression levels of iNOS were analyzed by Western blot. A representative blot from three independent experiments is shown. (C) RAW264.7 cells were cultured in the presence of LPS for $6 \mathrm{~h}$ after being pretreated with CVB-D for $1 \mathrm{~h}$. The mRNA levels of iNOS were determined by RT-PCR. (D) After macrophages were treated with CVB-D or AG490 for $24 \mathrm{~h}$, cell viability was examined using the MTT assay. The results were presented as the mean \pm SD for three independent experiments. ${ }^{b} P<0.05,{ }^{c} P<0.01$, compared to the LPS group.

regulatory roles in the macrophage-mediated inflammatory response ${ }^{[19]}$. NF- $\mathrm{kB}$ is normally present in the cytosol in an inactive form linked to inhibitor $\kappa B$ (ІкB) protein. In response to an activation signal, the IкB protein is degraded. NF- $\mathrm{KB}$ is then released from the NF- $\mathrm{KB} / \mathrm{I \kappa B}$ complex and translocates into the nucleus, regulating the transcription of a large number of genes, including those that encode pro-inflammatory mediators. In our study, the protein levels of ІкB- $\alpha$ and the p65 subunit of NF-kB in the cytoplasm significantly decreased after LPS challenge for $30 \mathrm{~min}$, and the p65 protein level in the nucleus markedly increased, indicating that the p65 subunit was translocated into the nucleus (Figure 3A). Pretreatment with CVB-D (50-200 $\mu \mathrm{mol} / \mathrm{L})$ had no distinct effect on this degradation and translocation. In addition, $8 \mathrm{~h}$ of LPS treatment resulted in a 7-fold increase in NF-kB transcriptional activity, as determined by measuring the luciferase activity of the reporter plasmid, and CVB-D did not affect this response (Figure 3B).
CVB-D did not inhibit the phosphorylation of MAPKs in LPSstimulated RAW264.7 cells

MAPK cascades are known to be critical for LPS-stimulated induction of inflammatory mediators in RAW264.7 cells $^{[20]}$. To determine whether the CVB-D-induced anti-inflammatory effect is mediated by MAPK pathways, we subsequently evaluated the effects of CVB-D on the phosphorylation of ERK1/2, p38, and JNK MAPKs in LPS-stimulated RAW 264.7 cells. As shown in Figure 4, LPS significantly promoted the phosphorylation of ERK1/2, JNK, and p38 MAPKs in RAW 264.7 cells. Pretreatment with CVB-D did not inhibit the phosphorylation of MAPKs. The total protein expression of ERK1/2, p38, and JNK MAPKs was unaffected by LPS or LPS in combination with CVB-D.

CVB-D inhibited JAK-STAT pathway activation in LPS-stimulated RAW264.7 cells

The inhibition of the JAK-STAT pathway has been reported 
A
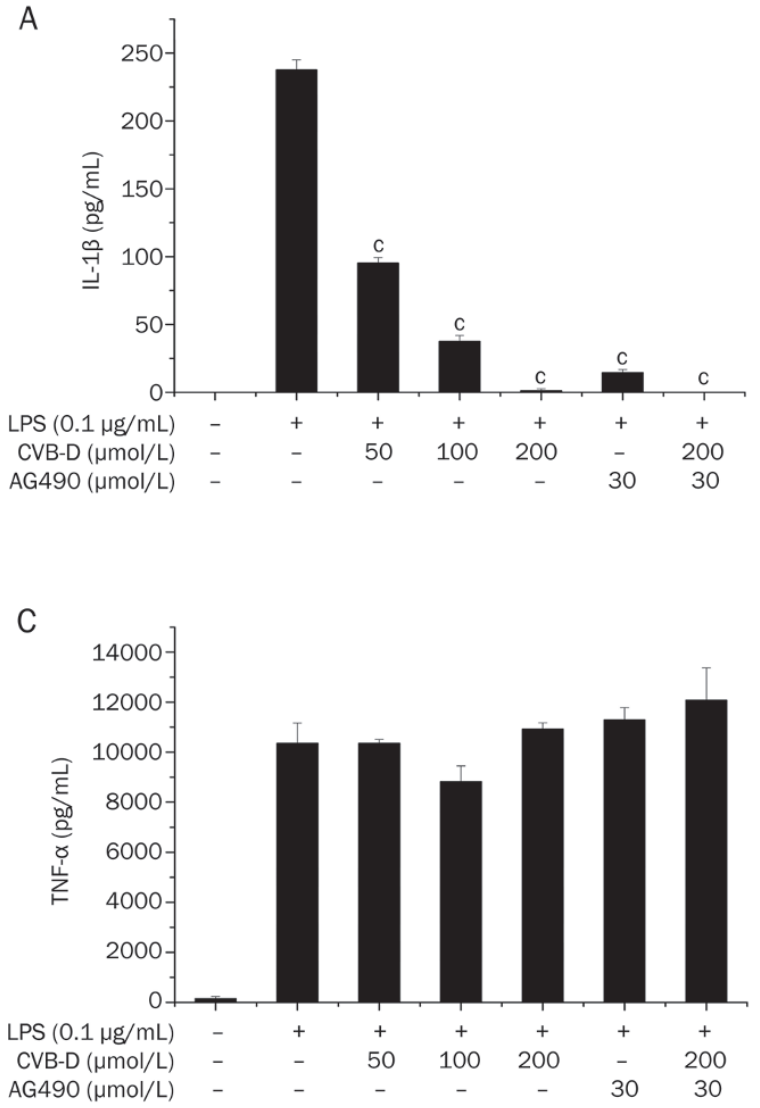
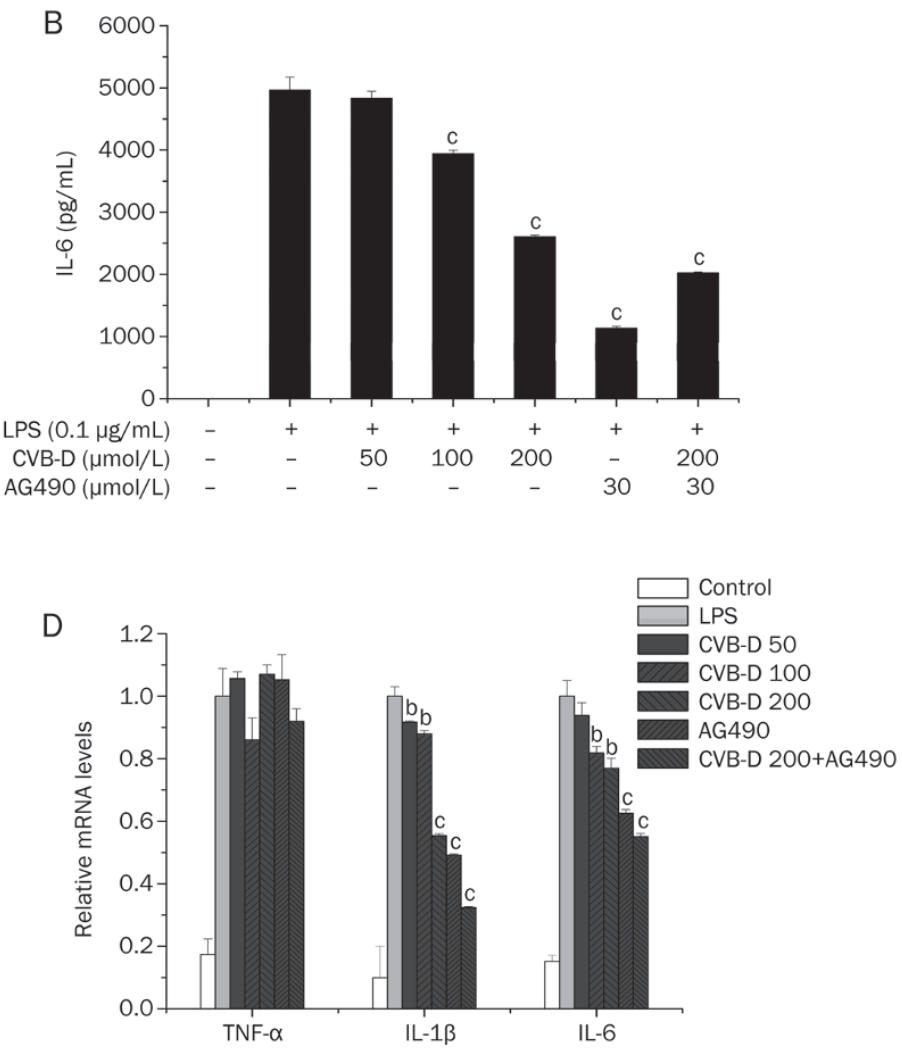

Figure 2. The effect of CVB-D on IL-1 $1 \beta$, IL-6, and TNF- $\alpha$ gene expression and protein secretion in LPS-stimulated RAW264.7 cells. The cells were treated with CVB-D $(50-200 \mu \mathrm{mol} / \mathrm{L})$ and LPS $(0.1 \mu \mathrm{g} / \mathrm{mL})$. The levels of IL-1 $\beta$, IL-6, and TNF- $\alpha$ were measured using ELISA. Real-time PCR was performed to determine mRNA expression of the cytokines. The effects of CVB-D on the secretion of (A) IL-1B, (B) IL-6, and (C) TNF- $\alpha$ and (D) the mRNA expression of each of these proteins are shown. The data represent the mean \pm SD of triplicate experiments. ${ }^{b} P<0.05,{ }^{c} P<0.01$ compared to the LPS group.

to result in suppression of LPS-induced expression of NO, IL-1 $\beta$, and IL- 6 but not TNF- $\alpha$ or COX- $2^{[21-24]}$, which is consistent with the anti-inflammatory profile of CVB-D found in our study. The specific JAK2 inhibitor AG490 was also found to have similar effects in inhibiting gene expression and protein secretion of inflammatory mediators. These results encouraged us to investigate the effect of CVB-D on the activation of the JAK-STAT pathway.

As shown in Figure 5A, phosphorylation of STAT1 and STAT3 started at 1-2 $\mathrm{h}$ after LPS challenge and peaked at $6 \mathrm{~h}$, whereas significant phosphorylation of JAK2 was detected at approximately $15 \mathrm{~min}$ after LPS stimulation. CVB-D significantly blocked the phosphorylation of JAK2, as well as the subsequent phosphorylation of STAT1 and STAT3, in a concentration-dependent manner. However, no distinct effect was observed on total JAK2, STAT1, and STAT3 protein level (Figure 5B).

\section{Discussion}

In the present study, we found that CVB-D suppressed the production of inflammatory mediators (NO, IL-1 $\beta$, and IL-6) in a dose-dependent manner in LPS-stimulated RAW 264.7 cells. These results reveal, for the first time, that CVB-D iso- lated from Buxus sinica exhibits anti-inflammatory properties in vitro. The underlying mechanisms appear to be attributable to the blockade of the JAK-STAT pathway.

NO induced by iNOS is involved in a broad spectrum of pathophysiological processes, including atherosclerosis ${ }^{[25]}$, diabetes $^{[26]}$ and septic shock ${ }^{[27]}$. NO and iNOS induction have also been reported to contribute to the process of cell injury in myocardial infarction and heart failure ${ }^{[28]}$. Blocking NO production by inhibiting iNOS activity may be a valid way of treating myocardial infarction. PGE2 generated by COX-2 is another important mediator contributing to vasodilation, pain and fever in inflammation. In our study, CVB-D effectively decreased NO production by suppressing the mRNA and protein expression of iNOS in LPS-stimulated RAW264.7 cells but did not affect COX-2 expression at either the protein or gene levels. These results indicate that the specific inhibition of iNOS protein and gene expression may be responsible for the anti-inflammatory activity of CVB-D, and this inhibitory effect may be involved in its cardioprotective role.

The cytokine-mediated inflammatory responses play important roles in cardiac remodeling and heart failure. Effects of antagonists against the pro-inflammatory cytokines, such as IL-1 $\beta$, IL-6, or TNF- $\alpha$, in patients and animal models of coro- 
A
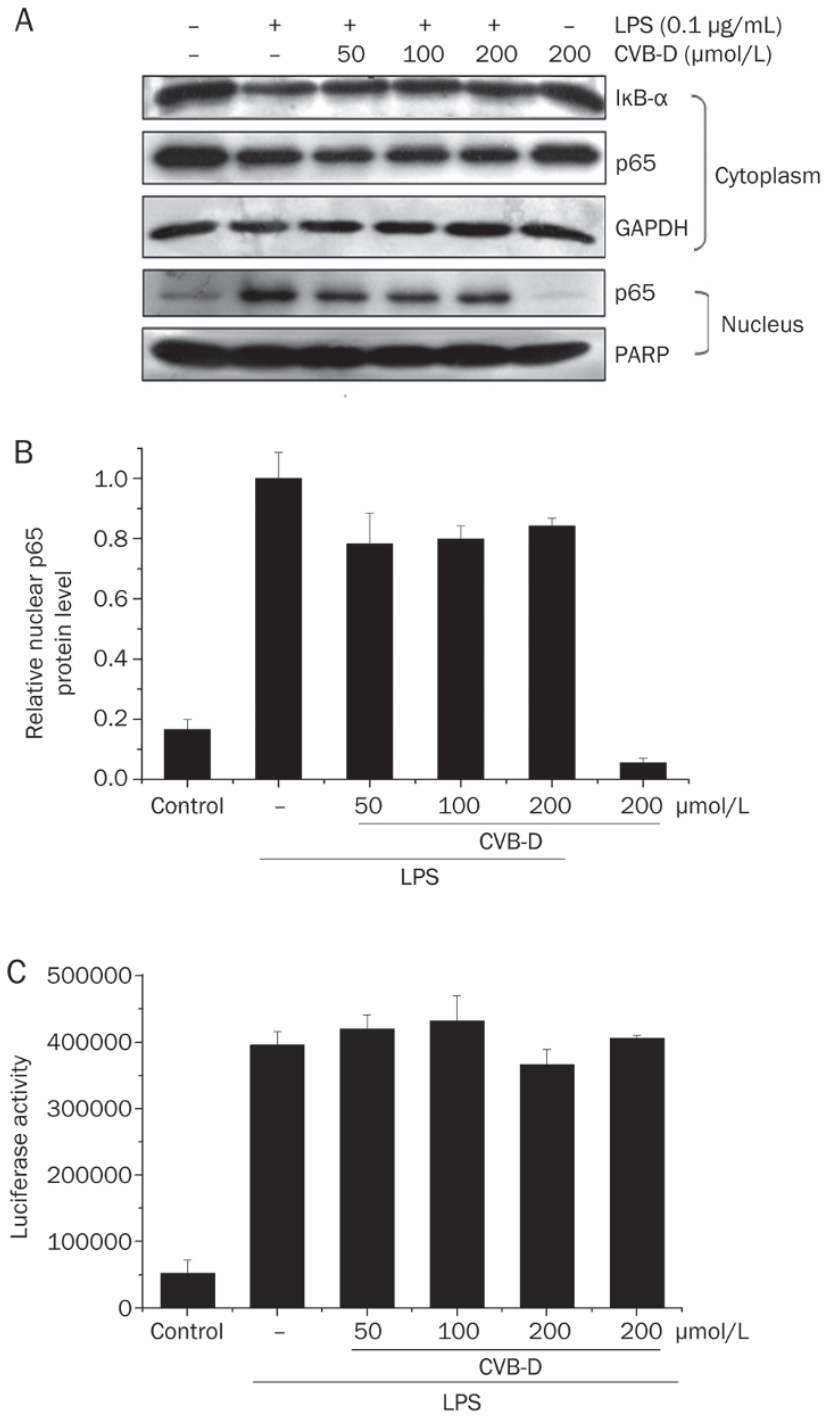

Figure 3. The effect of CVB-D on the LPS-induced activation of the NF-KB pathway in RAW264.7 Cells. (A) Cells were pretreated with CVB-D (50-200 $\mu \mathrm{mol} / \mathrm{L})$ for $1 \mathrm{~h}$ before $30 \mathrm{~min}$ of LPS $(0.1 \mu \mathrm{g} / \mathrm{mL})$ stimulation. The protein levels of NF-KB p65 and IKB- $\alpha$ in the cytoplasm and p65 in the nucleus were detected by Western blot. GAPDH and PARP were used as internal controls in the cytoplasm and nucleus, respectively. A representative blot from three independent experiments is shown. (B) Cells were transfected with the pNF-KB-luciferase plasmid. After $1 \mathrm{~h}$ of pretreatment with CVB-D and $8 \mathrm{~h}$ following incubation with LPS, the cells were lysed and luciferase activity was determined. The data represent the mean \pm SD of triplicate experiments. ${ }^{\mathrm{b}} P<0.05,{ }^{\mathrm{C} P}<0.01$ compared to the LPS group.

nary artery disease and acute myocardial infarction have been evaluated ${ }^{[29-31]}$. IL-1 blockade was found to be effective in limiting atherosclerosis and atherothrombosis and improves outcomes in acute myocardial infarction and ischemic stroke ${ }^{[32,33]}$. In our study, CVB-D greatly inhibited the production and mRNA expression of IL-1 $\beta$ and, to a lesser extent, IL-6 in LPSstimulated RAW264.7 cells. However, CVB-D showed no significant effect on LPS-induced TNF- $a$ secretion and gene expression. These data suggest that CVB-D may ameliorate

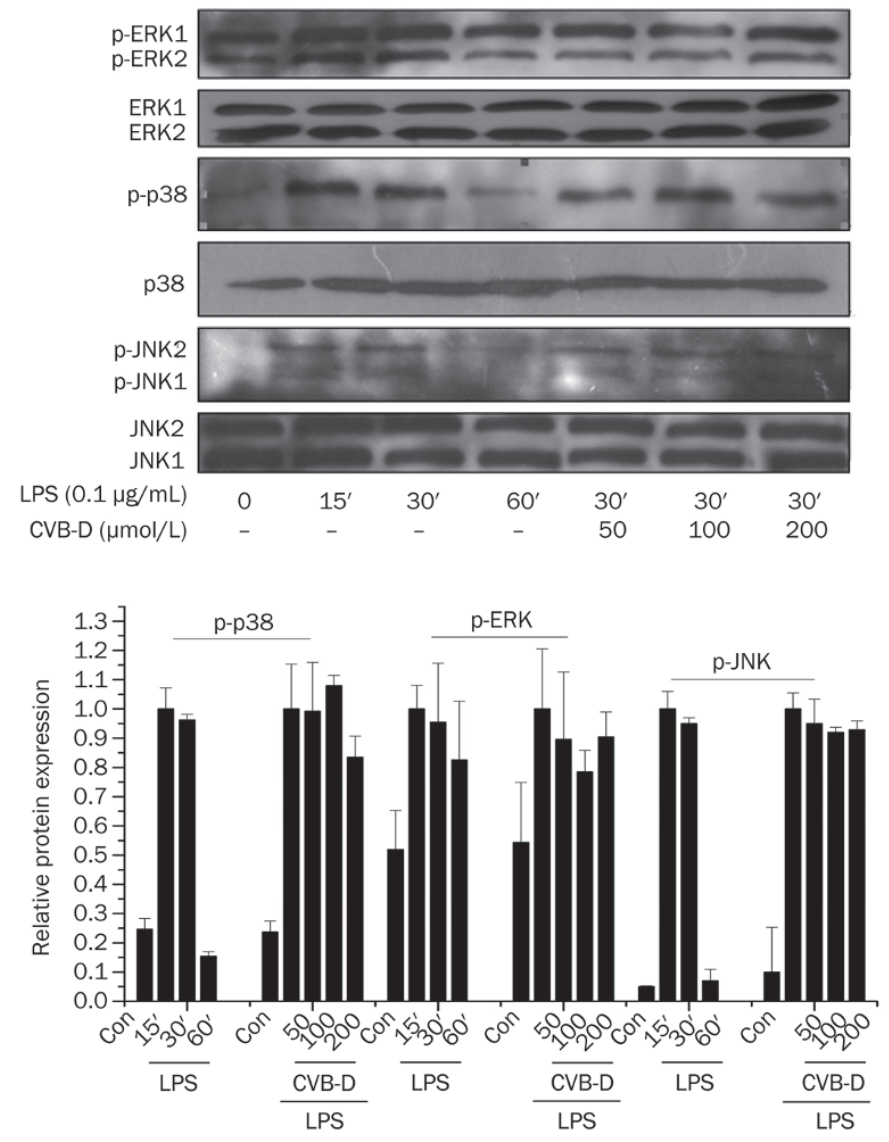

Figure 4. The effect of CVB-D on LPS-induced phosphorylation of MAPKs in RAW264.7 cells. Cells were pretreated with CVB-D $(50-200 \mu \mathrm{mol} / \mathrm{L})$ for $1 \mathrm{~h}$ and stimulated with LPS $(0.1 \mu \mathrm{g} / \mathrm{mL})$ for the indicated time points. The levels of phosphorylated and total p38, JNK, and ERK1/2 were assessed by Western blot. The data represent the mean \pm SD of triplicate experiments. ${ }^{\mathrm{b}} P<0.05,{ }^{\mathrm{c}} P<0.01$ compared to the LPS group. A representative blot from three independent experiments is shown.

inflammation-related disorders, including myocardial infarction and heart failure, by modulating IL- $1 \beta$ and IL- 6 expression.

To further explore the mechanism underlying the antiinflammatory effect of CVB-D, our studies focused on the NF-kB, MAPK, and JAK-STAT inflammatory pathways. We determined that CVB-D showed no inhibitory effect on the LPS-activated MAPK pathways, including the phosphorylation of ERK1/2, p38, and JNK in RAW264.7 cells. CVB-D also had no impact on LPS-stimulated ІкB-a degradation and the subsequent NF-KB transcriptional activity in RAW264.7 cells. Taken together, we show that CVB-D suppresses inflammatory mediator expression via a mechanism independent of the MAPK and NF-KB pathways in macrophages.

Previous studies have demonstrated that activation of the JAK2-STAT pathway results in LPS-mediated expression of NO, IL-1 $\beta$, and IL- 6 but not COX-2 and TNF- $a$. Our studies show that the effects exerted on the production of inflammatory mediators by CVB-D were similar to the effects of the specific JAK2 inhibitor AG490. Based on the above findings, we 
A
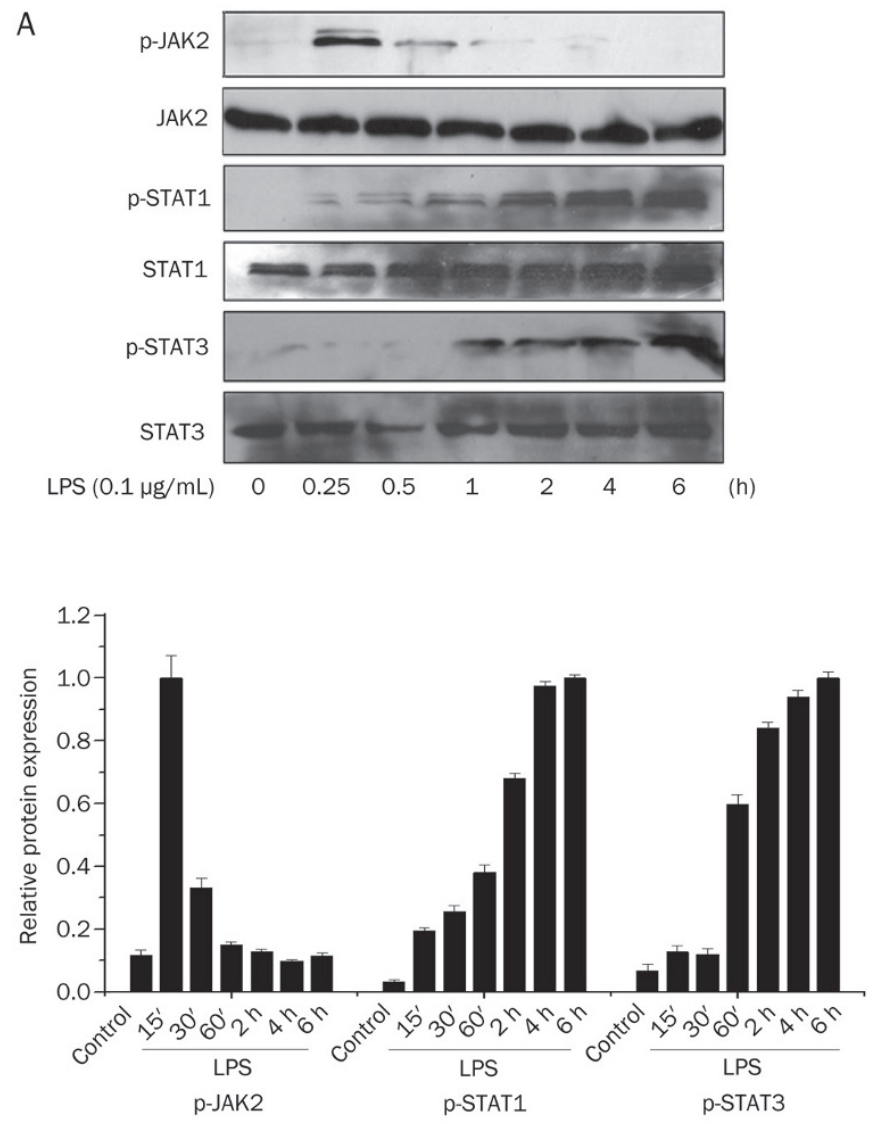

B

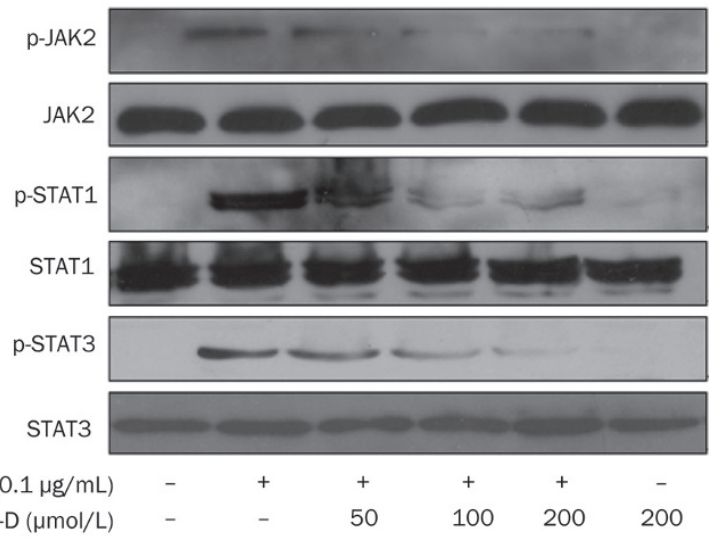

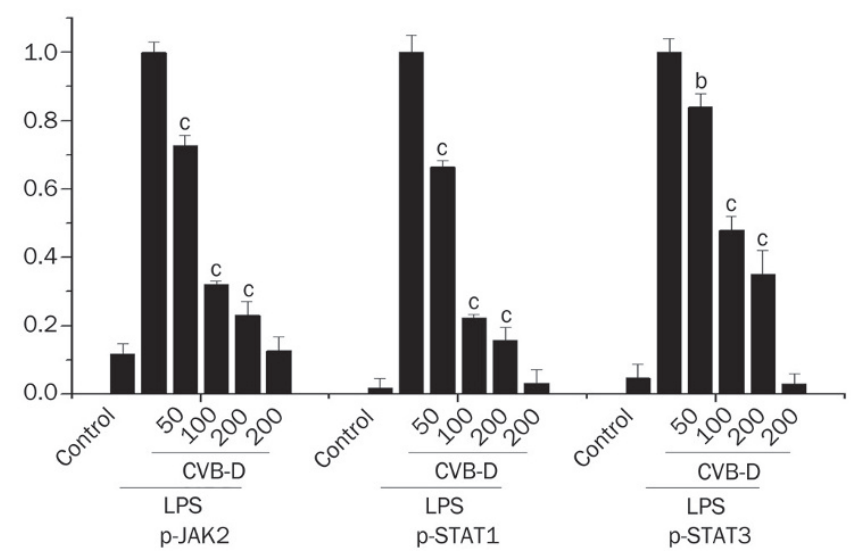

Figure 5. The inhibitory effect of CVB-D on LPS-mediated JAK2-STAT pathway activation in RAW264.7 cells. (A) After RAW264.7 cells were stimulated with LPS $(0.1 \mu \mathrm{g} / \mathrm{mL})$ for various lengths of time as indicated, the phosphorylation of JAK2, STAT1, and STAT3 was detected. Total JAK2, STAT1, and STAT3 were used as internal controls. (B) Cells were treated with different concentrations of CVB-D for $1 \mathrm{~h}$ before the addition of $0.1 \mu \mathrm{g} / \mathrm{mL}$ of LPS. Phosphorylated and total JAK2 levels were assessed at $15 \mathrm{~min}$, whereas phosphorylated and total STAT1 and STAT3 levels were assessed at $4 \mathrm{~h}$. The data represent the mean \pm SD of triplicate experiments. ${ }^{b} P<0.05,{ }^{c} P<0.01$, compared to the LPS group. A representative blot from three independent experiments is shown.

hypothesize that the main target of CVB-D is the JAK-STAT pathway.

Mammalian JAKs are composed of four members, among which JAK2 is the dominant member in macrophages. JAK2 is activated after RAW264.7 cells are stimulated with LPS, leading to the activation of the downstream molecules STAT1 and STAT3, which translocate into the nucleus to regulate the transcription of target genes encoding inflammatory mediators ${ }^{[34]}$. As expected, CVB-D markedly inhibited the phosphorylation of JAK2, STAT1, and STAT3 in LPS-stimulated RAW264.7 cells. We found that the activation of the JAK-STAT pathway caused by LPS occurred much later than the MAPK and NF-kB pathways in macrophages. A 15-min exposure to LPS resulted in a significant increase in the phosphorylation of JNK, p38, and ERK. Degradation of IKB- $\alpha$ and nuclear translocation of p65 NF-kB were distinct within $30 \mathrm{~min}$ after LPS stimulation. However, tyrosine phosphorylation of STAT1 and STAT3 was detected at $1-2 \mathrm{~h}$, and $6 \mathrm{~h}$ was required to reach the maximum levels of phosphorylation after exposure to LPS (Figure 5A). This result implies that the expression of inflammatory media- tors that respond early to LPS stimulation, such as TNF- $\alpha$, may be more dependent on MAPK and NF-kB than on the JAKSTAT signaling pathways. Previous studies have shown that IL-1 $\beta$, IL-6, and iNOS, but not TNF- $\alpha$, contain STAT binding elements in their promoter regions and that JAK2-STATs play a critical role in the LPS-induced expression of IL-1 $\beta$, IL-6, and iNOS, with little effect on TNF- $\alpha$ expression ${ }^{[35,36]}$. All these results support our hypothesis that CVB-D suppresses IL-1 $\beta$, IL-6 and iNOS expression by blocking the JAK-STAT pathway in LPS-stimulated macrophages.

The activation of the JAK-STAT pathway leads to the production of several inflammatory mediators. Meanwhile, some pro-inflammatory cytokines, including members of the IL-6 family, may activate this signal pathway, mediating diverse biological responses ${ }^{[37]}$. Therefore, the inhibitory action of CVB-D on the JAK-STAT pathway results in its strong antiinflammatory effects. Because unrestrained inflammation in the infarcted heart induces cardiomyocyte apoptosis and matrix degradation, down modulation of cytokine responses by blocking the JAK-STAT pathway may be an effective way 
to protect the myocardium from dilative remodeling and progressive dysfunction. Suppression of JAK-STAT pathway activation is reported to result in protection against myocardial injury in rat acute myocardial infarction and septic shock ${ }^{[38,39]}$. CVB-D is widely used in treating cardiac insufficiency, arrhythmias, coronary heart disease and myocardial infarction in China. Our study first implies that the anti-inflammatory effect of CVB-D is mediated by suppressing the activation of the JAK-STAT pathway, a mechanism that may facilitate its role in cardioprotection.

In conclusion, the present study demonstrates that CVB-D inhibits the LPS-induced inflammatory response in RAW264.7 macrophages by blocking the JAK-STAT pathway, and this effect may be involved in its cardioprotection in myocardial infarction and heart failure. These findings provide new insight into the anti-inflammatory activity of CVB-D and its mechanism in heart disease. Further studies are needed to explore how the anti-inflammatory action of CVB-D affects its roles in myocardial infarction.

\section{Acknowledgements}

This study is supported by grants from the Guangdong Natural Science Foundation (№ S2011010003787, S2012010009056), Science and Technology Planning Project of Guangdong Province (№ 2011B031800128), Science and Technology Bureau of Guangzhou (№ 2011J4100085), and Science and Technology Bureau of Baiyun District of Guangzhou (№ 2011-KZ-60).

\section{Author contribution}

Dan GUO performed most of the experiments, analyzed the data and drafted the manuscript; Jing-rong LI and Ying WANG performed some of the experiments and statistical analysis; Chuan-lin YU and Lin-sheng LEI assisted in the experiments; Na-na CHEN designed the study and reviewed the manuscript.

\section{References}

1 Szliszka E, Skaba D, Czuba ZP, Krol W. Inhibition of inflammatory mediators by neobavaisoflavone in activated RAW264.7 macrophages. Molecules 2011; 16: 3701-12.

2 Yun KJ, Kim JY, Kim JB, Lee KW, Jeong SY, Park HJ, et al. Inhibition of LPS-induced NO and PGE2 production by asiatic acid via NF-kappa B inactivation in RAW 264.7 macrophages: possible involvement of the IKK and MAPK pathways. Int Immunopharmacol 2008; 8: 431-41.

3 Shin KM, Kim YH, Park WS, Kang I, Ha J, Choi JW, et al. Inhibition of methanol extract from the fruits of Kochia scoparia on lipopolysaccharide-induced nitric oxide, prostaglandin [correction of prostagladin] E2, and tumor necrosis factor-alpha production from murine macrophage RAW 264.7 cells. Biol Pharm Bull 2004; 27 : 538-43.

4 Ryu B, Li Y, Qian ZJ, Kim MM, Kim SK. Differentiation of human osteosarcoma cells by isolated phlorotannins is subtly linked to COX2, iNOS, MMPs, and MAPK signaling: implication for chronic articular disease. Chem Biol Interact 2009; 179: 192-201.

5 Zhao L, Wang X, Chang Q, Xu J, Huang Y, Guo Q, et al. Neferine, a bisbenzylisoquinline alkaloid attenuates bleomycin-induced pulmonary fibrosis. Eur J Pharmacol 2010; 627: 304-12.
6 Kempf T, Zarbock A, Vestweber D, Wollert KC. Anti-inflammatory mechanisms and therapeutic opportunities in myocardial infarct healing. J Mol Med (Berl) 2012; 90: 361-9.

7 Frangogiannis NG. Regulation of the inflammatory response in cardiac repair. Circ Res 2012; 110: 159-73.

8 Zhou JY, Liao HF, Huang GY. A pharmacology study of cyclovirobuxinum $\mathrm{D}$ on curing myocardial ischemia induced by isoprenaline. Zhong Yao Cai 2006; 29: 1218-20.

9 Zhou JY, Sun YD, Tan YH, Deng SJ, Huang GY. The effect of cyclovirobuxinum $\mathrm{D}$ on myocardial ischemia induced by coronary artery ligation in rats. Zhong Yao Cai 2007; 30: 828-30.

$10 \mathrm{Hu}$ D, Liu X, Wang Y, Chen S. Cyclovirobuxine D ameliorates acute myocardial ischemia by $\mathrm{K}_{\text {ATP }}$ channel opening, nitric oxide release and anti-thrombosis. Eur J Pharmacol 2007; 569: 103-9.

11 Yu B, Fang TH, Lu GH, Xu HQ, Lu JF. Beneficial effect of cyclovirobuxine $D$ on heart failure rats following myocardial infarction. Fitoterapia 2011; 82: 868-77.

12 Yu B, Ruan M, Zhou L, Xu L, Fang T. Influence of cyclovirobuxine D on intracellular $[\mathrm{Ca}(2+)]$ regulation and the expression of the calcium cycling proteins in rat myocytes. Fitoterapia 2012; 83: 1653-65.

13 Christia P, Frangogiannis NG. Targeting inflammatory pathways in myocardial infarction. Eur J Clin Invest 2013; 43: 986-95.

14 Klingenberg R, Luscher TF. Inflammation in coronary artery disease and acute myocardial infarction - is the stage set for novel therapies? Curr Pharm Des 2012; 18: 4358-69.

15 Choi YH, Jin GY, Li GZ, Yan GH. Cornuside suppresses lipopolysaccharide-induced inflammatory mediators by inhibiting nuclear factor-kappa B activation in RAW 264.7 macrophages. Biol Pharm Bull 2011; 34: 959-66.

16 Okugawa S, Ota Y, Kitazawa T, Nakayama K, Yanagimoto S, Tsukada $\mathrm{K}$, et al. Janus kinase 2 is involved in lipopolysaccharide-induced activation of macrophages. Am J Physiol Cell Physiol 2003; 285: C399-408.

17 Guha M, Mackman N. LPS induction of gene expression in human monocytes. Cell Signal 2001; 13: 85-94.

18 Archer S. Measurement of nitric oxide in biological models. FASEB J 1993; 7: 349-60.

19 Tak PP, Firestein GS. NF-kappaB: a key role in inflammatory diseases. J Clin Invest 2001; 107: 7-11.

20 Han JM, Jin YY, Kim HY, Park KH, Lee WS, Jeong TS. Lavandulyl flavonoids from Sophora flavescens suppress lipopolysaccharideinduced activation of nuclear factor-kappaB and mitogen-activated protein kinases in RAW264.7 cells. Biol Pharm Bull 2010; 33: 101923.

21 Samavati L, Rastogi R, Du W, Huttemann M, Fite A, Franchi L. STAT3 tyrosine phosphorylation is critical for interleukin 1 beta and interleukin-6 production in response to lipopolysaccharide and live bacteria. Mol Immunol 2009; 46: 1867-77.

22 Chiou WF, Don MJ, Liao JF, Wei BL. Psoralidin inhibits LPS-induced iNOS expression via repressing Syk-mediated activation of PI3K-IKKIkappaB signaling pathways. Eur J Pharmacol 2011; 650: 102-9.

23 Tsoyi K, Kim HJ, Shin JS, Kim DH, Cho HJ, Lee SS, et al. HO-1 and JAK2/STAT-1 signals are involved in preferential inhibition of iNOS over COX-2 gene expression by newly synthesized tetrahydroisoquinoline alkaloid, CKD712, in cells activated with lipopolysacchride. Cell Signal 2008; 20: 1839-47.

24 Uto T, Fujii M, Hou DX. 6-(Methylsulfinyl)hexyl isothiocyanate suppresses inducible nitric oxide synthase expression through the inhibition of Janus kinase 2-mediated JNK pathway in lipopolysaccharide-activated murine macrophages. Biochem Pharmacol 2005; 70: 1211-21. 
25 Bai N, Kido T, Kavanagh TJ, Kaufman JD, Rosenfeld ME, van Breemen $\mathrm{C}$, et al. Exposure to diesel exhaust up-regulates iNOS expression in ApoE knockout mice. Toxicol Appl Pharmacol 2011; 255: 184-92.

26 Soskic SS, Dobutovic BD, Sudar EM, Obradovic MM, Nikolic DM, Djordjevic JD, et al. Regulation of inducible nitric oxide synthase (iNOS) and its potential role in insulin resistance, diabetes and heart failure. Open Cardiovasc Med J 2011; 5: 153-63.

27 Yeh CH, Chou W, Chu CC, So EC, Chang HC, Wang JJ, et al. Anticancer agent 2-methoxyestradiol improves survival in septic mice by reducing the production of cytokines and nitric oxide. Shock 2011; 36: 510-6.

28 Guo Y, Sanganalmath SK, Wu W, Zhu X, Huang Y, Tan W, et al. Identification of inducible nitric oxide synthase in peripheral blood cells as a mediator of myocardial ischemia/reperfusion injury. Basic Res Cardiol 2012; 107: 253.

29 Abbate A, Salloum FN, Vecile E, Das A, Hoke NN, Straino S, et al. Anakinra, a recombinant human interleukin-1 receptor antagonist, inhibits apoptosis in experimental acute myocardial infarction. Circulation 2008; 117: 2670-83.

30 Smolen JS, Beaulieu A, Rubbert-Roth A, Ramos-Remus C, Rovensky $J$, Alecock E, et al. Effect of interleukin-6 receptor inhibition with tocilizumab in patients with rheumatoid arthritis (OPTION study): a double-blind, placebo-controlled, randomised trial. Lancet 2008; 371: 987-97.

31 Mann DL, McMurray JJ, Packer M, Swedberg K, Borer JS, Colucci WS, et al. Targeted anticytokine therapy in patients with chronic heart failure: results of the Randomized Etanercept Worldwide Evaluation (RENEWAL). Circulation 2004 ; 109: 1594-602.

32 Abbate A, Kontos MC, Grizzard JD, Biondi-Zoccai GG, Van Tassell
BW, Robati R, et al. Interleukin-1 blockade with anakinra to prevent adverse cardiac remodeling after acute myocardial infarction (Virginia Commonwealth University Anakinra Remodeling Trial [VCU-ART] Pilot study). Am J Cardiol 2010; 105: 1371-7.

33 Abbate A, Van Tassell BW, Biondi-Zoccai GG. Blocking interleukin-1 as a novel therapeutic strategy for secondary prevention of cardiovascular events. Biodrugs 2012; 26: 217-33.

34 Ihle JN. The Stat family in cytokine signaling. Curr Opin Cell Biol 2001; 13: 211-7.

35 Kou X, Qi S, Dai W, Luo L, Yin Z. Arctigenin inhibits lipopolysaccharideinduced iNOS expression in RAW264.7 cells through suppressing JAKSTAT signal pathway. Int Immunopharmacol 2011; 11: 1095-102.

36 Lee C, Lim HK, Sakong J, Lee YS, Kim JR, Baek SH. Janus kinasesignal transducer and activator of transcription mediates phosphatidic acid-induced interleukin (IL)-1beta and IL-6 production. Mol Pharmacol 2006; 69: 1041-7.

37 Gorina R, Petegnief V, Chamorro A, Planas AM. AG490 prevents cell death after exposure of rat astrocytes to hydrogen peroxide or proinflammatory cytokines: involvement of the Jak2/STAT pathway. J Neurochem 2005; 92: 505-18.

38 Zhang S, Liu X, Goldstein S, Li Y, Ge J, He B, et al. Role of the JAK/ STAT signaling pathway in the pathogenesis of acute myocardial infarction in rats and its effect on NF-kappaB expression. Mol Med Rep 2013; 7: 93-8

39 Zhang $M$, Wang $X$, Wang X, Hou X, Teng P, Jiang $Y$, et al. Oxymatrine protects against myocardial injury via inhibition of JAK2/STAT3 signaling in rat septic shock. Mol Med Rep 2013; 7: 1293-9. 